Revista

Ibero-Americana

de Estratégıa
DOI: $10.5585 /$ riae.v12i4.1951

Organização: Comitê Científico Interinstitucional

Editor Científico: Benny Kramer Costa

Avaliação: Double Blind Review pelo SEER/OJS

Revisão: Gramatical, normativa e de formatação

\title{
O PENSAMENTO ESTRATÉGICO NO SÉCULO XX: EXPLICAÇÕES HISTÓRICAS
}

STRATEGY IN THE 20 ${ }^{\text {TH }}$ CENTURY: EXPLANATIONS FROM HISTORY

PENSAMIENTO ESTRATÉGICO EN SIGLO XX: EXPLICACIÓN HISTÓRICA

\section{Leonardo Silveira Conke}

Mestre em Administração pela Universidade Federal do Paraná - UFPR

Professor da Universidade de Brasília

E-mail: leoconke@unb.br (Brasil) 


\section{O PENSAMENTO ESTRATÉGICO NO SÉCULO XX: EXPLICAÇÕES HISTÓRICAS}

\section{RESUMO}

Considerando a relação entre as organizações e seu ambiente admite-se, neste ensaio, que o estudo do contexto histórico auxilia no entendimento dos motivos pelos quais elas realizam determinadas escolhas. Assim, tem-se como objetivo situar historicamente as principais teorias e ferramentas estratégicas desenvolvidas a partir do século XX, descrevendo como os fatos da história geral (relacionados à economia, cultura, política, tecnologia etc.) influenciaram no seu surgimento, na sua aceitação, na sua expansão ou na sua consolidação. Normalmente, a história tradicional é preterida nos textos da Administração, limitando-se às explicações sobre a Revolução Industrial e à transição do feudalismo para o capitalismo. Neste artigo, a extensa pesquisa bibliográfica permitiu oferecer explicações adicionais, baseadas em acontecimentos históricos marcantes, para a evolução ocorrida no pensamento estratégico a partir do século XX. Como resultado, foram percebidos quatro momentos nos quais há um alinhamento mais nítido entre os desafios criados pelas condições históricas e as estratégias oportunamente propostas para enfrentá-los: no primeiro período (19001938) a preocupação com a organização e o controle das atividades empresariais aproxima a estratégia da Administração Científica; o segundo (1939-1964), é marcado pela formalização do planejamento e pelo reconhecimento da área; nas décadas seguintes (1965-1989), a competição e a incerteza exigem estratégias voltadas aos problemas externos, desenvolvidas principalmente pelas consultorias; no último período (1990-2010), caracterizado pela disponibilidade ilimitada de dados e informações, o conhecimento e a prática dos estrategistas tornam-se indispensáveis. Nas considerações finais, são apresentadas duas possíveis tendências estratégicas dos próximos anos.

Palavras-chave: História da Estratégia; Evolução da Estratégia; Teoria Estratégica.

\section{STRATEGY IN THE 20 ${ }^{\text {TH }}$ CENTURY: EXPLANATIONS FROM HISTORY}

\section{ABSTRACT}

In this essay, we argue that an historical perspective helps to understand some of the strategic choices made by organizations. More specifically, the purpose here is to describe the great influence of historical events (related to economy, politics, technological advancement etc.) on the creation, acceptance, spreading and / or establishment of the strategic theories and tools developed since the beginning of the $20^{\text {th }}$ century. Texts that usually discuss management and history outline only the Industrial Revolution or the transition from feudalism to capitalism, underestimating other historical forces that offer additional explanations to the evolution of strategic thinking. As a result of an extensive bibliographical research, we were able to identify four periods where the strategic theories developed reveal suitable responses to the challenges created by the environment: in the first one (1900-1938), strategy is concerned with organization and control of business activities, resembling the ideas developed by Scientific Administration; in the second period (1939-1964), strategic planning is formalized and the area is broadly recognized; the next decades (1965-1989) are characterized by competition and uncertainty, making strategy focus on problems emerged from the outside; finally, on the turn of the century (1990-2010), the unlimited information availability enhances the need for strategists' conceptual and practical knowledge. Also, as a final contribution, we suggest two possible trends to the future of strategy.

Keywords: Strategy History; Strategy Evolution; Strategic Theory. 


\section{PENSAMIENTO ESTRATÉGICO EN SIGLO XX: EXPLICACIÓN HISTÓRICA}

\section{RESUMEN}

Teniendo en cuenta la relación entre las organizaciones y su entorno son aceptables, en este ensayo, que el estudio del contexto histórico ayuda a entender las razones por las que realizan ciertas opciones. Por lo tanto, el objetivo ha situar históricamente las principales teorías y herramientas estratégicas desarrolladas a partir del siglo XX, que describe cómo los hechos de la historia general (relacionado con la economía, la cultura, la política, la tecnología, etc . ) Influenciado su apariencia, su aceptación en su expansión o consolidación. Por lo general, la historia tradicional ha quedado en desuso en los textos de Administración, limitado a las explicaciones de la Revolución Industrial y la transición del feudalismo al capitalismo. En este artículo, la extensa búsqueda en la literatura permitió ofrecer explicaciones adicionales, basados en eventos históricos importantes para la evolución del pensamiento estratégico del siglo XX. Como resultado, se percibieron cuatro momentos en los que hay una alineación clara entre los retos planteados por las condiciones históricas propuestas oportunas y estrategias para hacerles frente : en el primer período (1900-1938) la preocupación por la organización y el control de las actividades empresariales más cerca Estrategia de Gestión de la Ciencia , y la segunda (1939-1964) está marcada por la formalización de la planificación y el reconocimiento de la zona; durante las décadas siguientes (1965-1989), la competencia y la incertidumbre requieren estrategias orientadas a cuestiones externas , desarrolladas principalmente por consultores , en el último período (1990-2010), que se caracteriza por la disponibilidad ilimitada de datos y la información, el conocimiento y la práctica de los estrategas se vuelven indispensables. En la conclusión, se presentan dos posibles tendencias estratégicas de los próximos años.

Palabras-clave: Historia de la Estrategia; Desarrollo de Estrategia; Teoría Estratégica. 


\section{INTRODUÇÃO}

As organizações, quando vistas como sistemas abertos, devem a sua sobrevivência a um relacionamento apropriado, interativo e interdependente com o seu ambiente, pois importam recursos para seus domínios e devolvem produtos, serviços e resíduos. Considerando essa relação, as atividades de uma organização são definidas de acordo com a sua percepção do contexto no qual está inserida, já que as estruturas e comportamentos servem como respostas adaptativas às mudanças ambientais.

$\mathrm{O}$ mesmo ocorre com o pensamento estratégico, cuja evolução está relacionada às transformações na sociedade. Em outras palavras, o estudo das condições econômicas, culturais, demográficas, ecológicas etc. de determinado momento da história facilita o entendimento das decisões estratégicas tomadas nas organizações, as quais fazem tais escolhas de acordo com as suas necessidades naquele momento específico. Assim, o objetivo neste artigo, é situar historicamente as principais teorias e ferramentas estratégicas desenvolvidas a partir do século XX, descrevendo como os fatos da história geral (relacionados à economia, cultura, política, tecnologia etc.) influenciaram no seu surgimento, na sua aceitação, na sua expansão ou na sua consolidação.

No campo da Administração, a variável "história" é aproveitada de inúmeras formas. Inicialmente, a história dos negócios era um campo temático derivado da mais abrangente História Econômica, cujas questões são subjacentes à evolução das sociedades e dos Estados (Howell, 1995; Freitas-Filho, 1989). Atualmente, a abordagem mais difundida é aquela em que se mostra cronologicamente a evolução do pensamento em Administração, com o agrupamento em "escolas" de teorias conceitualmente próximas, como contemplado pela clássica disciplina de Teoria Geral da Administração ou por trabalhos como o de Mintzberg, Ahlstand e Lampel (2000), na área da estratégia. Existem ainda outras formas de se tratar a história, dentre as quais encontra-se: a história dos homens de negócios, que são biografias nas quais apresenta-se o administrador como um indivíduo inovador, portador de um papel social e criador de progresso econômico; a história setorial, com o relato da constituição de uma classe empresarial, suas ideologias, suas forças materiais e sua atuação político-social e; a história da empresa que, refeita frequentemente com base nos números e dados contábeis disponíveis, foca no conjunto de decisões tomadas ao longo do tempo em "uma” organização específica (Freitas-Filho, 1989).

Neste ensaio, entende-se a história na sua forma mais tradicional, i.e., como um conjunto de acontecimentos em um determinado período (Borges, 1993). Essa abordagem é menos frequente na literatura da Administração que, quando recorre à história geral, utiliza-a principalmente para 
retratar a $1^{\text {a }}$ Revolução Industrial e a transição do sistema feudalista para o capitalista, marcos relevantes para o surgimento da empresa moderna. Mesmo nos textos sobre pensamento estratégico, são explicitados os conceitos de cada teoria, seu funcionamento, a possibilidade de operacionalização e seus principais defensores, subestimando-se a influência (ou mesmo omitindose a existência) dos fatos históricos que permitiram o seu desenvolvimento.

Aproximar a relação entre o contexto histórico e o pensamento estratégico mostra-se relevante por completar a explicação de como determinadas teorias e ferramentas tornaram-se conhecidas e obtiveram repercussão e aval prático e acadêmico. Em alguns casos, a história esclarece as razões pelas quais algumas ideias só foram amplamente aceitas e reproduzidas apenas anos depois do seu surgimento, já que foram as condições históricas propícias que as tornaram eficazes para tratar os problemas enfrentados. De forma complementar, pode-se utilizar o relato histórico para um conhecimento preliminar da evolução do pensamento estratégico, que acompanhou o desenvolvimento da sociedade industrial e da organização moderna.

Outra contribuição é o reforço das conexões interdisciplinares do estudo das organizações com outros campos de estudo (como a economia, a política, a filosofia, o direito etc.), que proporcionam um contexto para o entendimento dos laços que as amarram à sociedade, fazendo-as fugir do isolamento e demonstrando claramente a sua inserção social, como lembrado em inúmeros trabalhos (Freitas-Filho, 1989; Howell, 1995; Clark \& Rowlinson, 2004; Booth \& Rowlinson, 2006). Mais especificamente, a aproximação com as visões provenientes da história tradicional ajuda na compreensão dos fenômenos administrativos e fortalece o desejado caráter interdisciplinar das pesquisas em Administração, criando vínculos mais profundos entre as áreas e evitando a adoção do universalismo (o reconhecimento do fenômeno organizacional como uniforme ao longo da história) e do presentismo (observação descontextualizada das organizações e das suas ações), vieses de percepção que prejudicam a formação dos gestores e pesquisadores sociais mais completos (Costa, Barros \& Martins, 2010; Barrett \& Srivastva, 1991; Zald, 1996).

De qualquer forma, a complexa relação entre as disciplinas torna indispensável a adoção de recortes históricos, especialmente adequados a este trabalho (Barros, 2004). O primeiro, temporal, refere-se à escolha de fatos históricos ocorridos a partir do século $\mathrm{XX}$, distinguindo-se de textos que remontam às antigas origens militares da estratégia. Aqui, o período escolhido coincide com o desenvolvimento formal da Administração, pois foi nessa época que tal área de estudos, da qual faz parte a estratégia, foi sistematizada a reconhecida como disciplina relevante para o entendimento da sociedade. Mesmo com essa limitação temporal, a interação entre os acontecimentos, que não podem ser unicamente econômicos, políticos, culturais etc., exigiu a escolha por uma exposição mais sintética daqueles fatos que, apesar de geograficamente pontuais em alguns casos, foram 
suficientemente marcantes a ponto de mudar as características da sociedade, priorizando-se, dessa forma, a relação entre a história e estratégia ao invés de detalhamentos descontextualizados.

O segundo recorte é metodológico, pois o uso exclusivo de extensa pesquisa bibliográfica mostrou-se compatível ao levantamento histórico necessário ao artigo. Inicialmente, foram selecionadas teorias e ferramentas estratégicas que possuem aparato conceitual e operacional suficiente para que possam ser reconhecidas como relevantes, e reproduzidas em diferentes situações. Essa primeira escolha deu-se pela análise de textos nos quais são apresentados conjuntos ou escolas de estratégia categorizadas. Em seguida, o esforço foi direcionado para a busca de dois tipos de trabalhos específicos: aqueles que representam a aparição inaugural das ideias ou que, supostamente retratam o seu desenvolvimento primeiro e; aqueles pelos quais elas tornaram-se mais conhecidas, que podem ou não coincidir com o primeiro grupo.

Assim, observando-se o objetivo proposto no artigo, e comparando-se os desafios criados pelas condições históricas e as estratégias oportunamente propostas para enfrentá-los, pôde-se determinar quatro períodos nos quais esse alinhamento é mais nítido, ou seja, nos quais os problemas gerados pelas mudanças no contexto histórico impulsionaram o surgimento, aceitação, expansão ou consolidação das teorias (Quadro). O primeiro período refere-se ao início do século (1900-1938), no qual a preocupação da estratégia é semelhante àquela da Administração Científica, qual seja de organizar e controlar a crescente atividade empresarial. O segundo período (1939-1964) é marcado pela consolidação da área de estratégia e pela aceitação do planejamento formal como instrumento essencial de administração. Nas décadas seguintes (1965-1989), os desafios estratégicos têm origem externa (competição e incerteza), e as organizações acabam recorrendo às soluções oferecidas pelas empresas de consultoria. Já na transição para o século XXI (1990-2010), o acesso ilimitado à informação torna o conhecimento conceitual e prático dos estrategistas o principal recurso capaz de gerar vantagem competitiva. Após a descrição dos quatro períodos, nas considerações finais, além dos comentários habituais de tal seção, são sugeridas duas possíveis tendências estratégicas, evidenciadas a partir de um exercício despretensioso de previsão. 


\begin{tabular}{|c|c|c|}
\hline PERÍODO & CONTEXTO HISTÓRICO & DESENVOLVIMENTO ESTRATÉGICO \\
\hline $\begin{array}{l}1900 \text { a 1938: } \\
\text { Início Produtivo }\end{array}$ & $\begin{array}{l}\text { O racionalismo é aplicado ao trabalho. } \\
\text { O crescimento pós } 1929 \text { e a } 1^{\text {a }} \text { Guerra } \\
\text { influenciam no surgimento dos } \\
\text { primeiros conglomerados e da } \\
\text { produção em larga escala. }\end{array}$ & $\begin{array}{l}\text { Os estrategistas estão parecidos aos } \\
\text { administradores científicos: racionais, } \\
\text { eficientes, conhecedores de estatística, } \\
\text { burocráticos e capazes de gerenciar muitos } \\
\text { funcionários especializados. }\end{array}$ \\
\hline $\begin{array}{l}1939 \text { a 1964: } \\
\text { A Formalização } \\
\text { do Planejamento }\end{array}$ & $\begin{array}{l}\text { A } 2^{\text {a }} \text { Guerra impulsionou a expansão } \\
\text { das empresas dos EUA. As operações } \\
\text { foram aumentadas e os donos das } \\
\text { empresas afastaram-se das operações } \\
\text { cotidianas e da administração. }\end{array}$ & $\begin{array}{l}\text { Surgem os administradores profissionais e a } \\
\text { estratégia formal, baseada na definição de } \\
\text { metas, objetivos e políticas. A principal } \\
\text { ferramenta desenvolvida é a análise SWOT. }\end{array}$ \\
\hline $\begin{array}{l}1965 \text { a 1989: } \\
\text { Competição e } \\
\text { Incerteza }\end{array}$ & $\begin{array}{l}\text { O período de crescimento e expansão } \\
\text { dá lugar à competição e à escassez. As } \\
\text { crises do petróleo de } 1973 \text { e } 1979 \\
\text { transformam as relações econômicas. }\end{array}$ & $\begin{array}{l}\text { Os problemas vêm do ambiente. Ferramentas } \\
\text { e teorias surgem nas consultorias para } \\
\text { otimizar o uso de recursos (e.g. } 5 \text { forças, } \\
\text { planejamento por cenários, análise de } \\
\text { portfólio e a teoria dos stakeholders). }\end{array}$ \\
\hline $\begin{array}{l}1990 \text { a 2010: } \\
\text { O Valor do } \\
\text { Conhecimento }\end{array}$ & $\begin{array}{l}\text { A } 3^{\mathrm{a}} \text { Revolução Industrial altera as } \\
\text { relações sociais. Existem muitas } \\
\text { informações disponíveis em tempo } \\
\text { real e as fronteiras entre os países } \\
\text { tornam-se cada vez menores. }\end{array}$ & $\begin{array}{l}\text { As organizações investem em recursos } \\
\text { internos, especialmente o conhecimento, } \\
\text { (teórico ou conceitual e prático). Surgem a } \\
\text { Visão Baseada em Recursos, a Administração } \\
\text { do Conhecimento e o Balanced Scorecard. }\end{array}$ \\
\hline
\end{tabular}

Quadro 1 - História e Estratégia no século XX: períodos selecionados Fonte: Elaborado pelo autor.

\section{A 1938: INÍCIO PRODUTIVO.}

A atividade estratégica do início do século $\mathrm{XX}$ resumia-se ao trabalho prático de responsabilidade dos homens de negócios. Historicamente, deve-se ressaltar o Racionalismo, a economia e a $1^{\text {a }}$ Guerra Mundial como fatores decisivos na formação dos estrategistas, cujas tarefas “confundiam-se" com as funções do administrador defendidas pela Escola Clássica da Administração.

Inaugurado por Descartes no século XVII, o Racionalismo atingiu seu apogeu no século XVIII, e só posteriormente foi aplicado às ciências naturais e às ciências sociais. As organizações e a própria Administração são frutos do racionalismo, pois "o desejo de racionalização do homem moderno atingiu todos os setores de sua vida, inclusive o da estrutura dos sistemas sociais de que 
participa" (Motta \& Bresser-Pereira, 1980, pp. 21-22). O campo do trabalho, que devido ao advento das máquinas havia se tornado mais eficiente, ainda não tinha sua organização e execução afetadas pelas ideias racionalistas, o que só veio a acontecer com os chamados fundadores da Administração Científica - Taylor, Fayol etc - (Motta, 1998). Foi uma época em que "o gerenciamento dos negócios passa a adquirir um caráter técnico-científico (...) que com seus métodos procurava obter um máximo de rendimento produtivo por operário" (Resende, 2007, p. 148).

A economia refletia as grandes mudanças da metade do século XIX, como a construção das estradas de ferro americanas e a $2^{\mathrm{a}}$ Revolução Industrial, que transformaram as relações comerciais. A reação foi em cadeia, causando a expansão ferroviária, estimulando o crescimento do setor metalomecânico e facilitando o aumento da demanda interna e o desenvolvimento da indústria de bens de produção e de consumo. O acesso ao capital e ao crédito permitiu investimentos em larga escala em insumos e produtos, utilizados para atender os mercados de massa (Ghemawat, 2002). Uma grande onda de inovações tecnológicas possibilitou a transmissão de eletricidade para iluminar as cidades e para suprir a demanda de energia das indústrias, incentivando o crescimento e transformando uma economia rural e agrária em industrial e urbana. Houve a criação de uma rede nacional de distribuição e vendas, e várias empresas foram obrigadas a desenvolver estruturas organizacionais específicas para seus objetivos. As estradas de ferro tornavam-se as primeiras grandes corporações, e o seu rápido crescimento forçou a adoção de complexos sistemas gerenciais e de uma gestão empresarial burocrática, exigindo administradores qualificados que pudessem resolver diversos problemas de controle e organização do trabalho em larga escala (Vizeu, 2010; Sears, 1956).

A $1^{\text {a }}$ Guerra Mundial também modificou a atividade estratégica. Até então o maior empreendimento conhecido pelo homem, uma guerra deveria ser organizada e administrada, o que requeria uma produção em massa igualmente organizada e administrada. O que era chamado de “economia de guerra" significava uma mobilização elevada dos fatores de produção nacionais, que não poderia ser mantida sem uma revolução na mão de obra e nos níveis de produtividade (Hobsbawm, 2008; Resende, 2007). Assim, além de acelerar o progresso de setores tecnológicos dos países beligerantes, como a aeronáutica e a computação, a Guerra serviu para intensificar as técnicas de controle de gastos e de demanda logística. A necessidade de coordenação entre os departamentos das empresas que supriam a produção bélica pressionou o uso de estatísticas e, nos anos seguintes à $1^{a}$ Guerra, a noção de orçamento já tinha se espalhado para ajudar no planejamento financeiro. $\mathrm{Na}$ academia, o interesse em temas como desempenho econômico, técnicas de inventário, produção e controle do mercado etc., refletia-se nos periódicos e nas escolas de 
administração. A Harvard Business School (HBS), por exemplo, iniciou em 1912 um curso que visava integrar os conhecimentos adquiridos em áreas funcionais como contabilidade, operações e finanças, dando ao aluno uma visão ampla dos problemas encontrados pelos executivos (Chandler \& Redlich, 1961).

De forma geral, as fábricas ficavam maiores: o número de funcionários multiplicava-se; a aquisição e a movimentação de materiais tornavam-se mais complexas; a produção em massa crescia; mais departamentos eram criados; havia uma maior diversificação dos produtos e uma ampliação da rede de distribuição e; investia-se mais em pesquisa e desenvolvimento. Esse aumento dos fatores de produção (máquinas, trabalhadores, insumos etc.) provocou a introdução de novas tarefas gerenciais, que deveriam contribuir para um controle mais adequado das atividades organizacionais. Uma das opções para lidar com tais mudanças era diminuir o tamanho das empresas, algo que não agradou, mesmo porque a economia passava por um período próspero de fusões e aquisições encorajadas pelos governos (Foster, 1985; Gras, 1936). A outra solução era racionalizar ainda mais os métodos de controle (dos custos, da produção, do estoque e da força de trabalho), o que ocorria discretamente desde as últimas décadas do século XIX com a chamada Administração Sistemática (Nelson, 1974).

O contexto histórico que motivou o crescimento das organizações também ajuda na compreensão do tipo de estrategista existente. Um bom executivo seria generalista, tecnicamente preparado para lidar com controle estatístico e contábil, capaz de planejar cuidadosamente seus passos, organizar racionalmente as tarefas e comandar seus subordinados, a fim de manter e dar continuidade às operações por meio da coordenação formal (Vizeu, 2010; Tedlow, Bettcher \& Purrington, 2003; Motta, 1998; Barnard 1938). Eles estavam assumindo grandes empresas, instituindo métodos burocráticos e gerenciando funcionários altamente especializados, o que levou à adoção de uma estrutura organizacional funcional, departamentalizada, centralizada e verticalmente integrada, que tornou-se dominante (Miles et al., 1997). As habilidades exigidas do estrategista da época assemelhavam-se às sugeridas pela Administração Científica, movimento que veio aperfeiçoar os métodos que já haviam sido desenvolvidos anteriormente pela Administração Sistemática.

Apesar de ter o seu crescimento amplamente associado aos EUA, principalmente devido aos trabalhos de Frederick W. Taylor, o movimento da Administração Científica não foi exclusivo aos ianques. A busca pela racionalização da produção e pela maior eficiência nos processos administrativos manifestou-se também na França (Fayol, 1930), na Alemanha e no Reino Unido (Kipping, 1997), no Japão (Sasaki, 1992), na China (Morgan, 2006), na União Soviética (Bedeian \& Phillips, 1990) e até no Brasil (Vargas, 1985). A presença, aceitação e reprodução dessas ideias em 
outros países, mesmo de forma mais moderada, reforça o argumento sobre a relação entre o contexto histórico e a estratégia, já que tanto os desafios enfrentados quanto as soluções encontradas eram semelhantes.

\section{A 1964: A FORMALIZAÇÃO DO PLANEJAMENTO.}

$\mathrm{O}$ advento da $2^{\mathrm{a}}$ Guerra Mundial propiciou uma aproximação entre o governo e academia, que pode ser percebida pelo alinhamento da HBS aos planos de guerra norte-americanos. A escola de negócios ofereceu disciplinas como "A Mobilização da Indústria” e "Os Problemas Econômicos da Defesa Nacional", em um curso pragmático, cujo propósito era garantir a formação de líderes (civis e militares) capazes de implementar eficazmente qualquer estratégia sob quaisquer condições, ajudando a reduzir a carência de homens treinados em gerenciamento e administração que pudessem servir como parceiros das forças armadas (Stevens, 2001). Contudo, foram os desdobramentos da Guerra que causaram maiores impactos no pensamento estratégico.

O saldo deixado pela $2^{\text {a }}$ Guerra foi devastador, com um mundo dividido entre capitalistas e socialistas e um custo material superior a um bilhão de dólares. A destruição causada levou a uma demanda excessiva, pois recuperar-se da guerra era a prioridade esmagadora dos países europeus (Hobsbawm, 2008). A partir da segunda metade dos anos 1940, houve uma reestruturação do capitalismo e um avanço na globalização da economia, o que multiplicou a capacidade produtiva mundial e tornou possível uma divisão internacional de trabalho mais elaborada e sofisticada. O comércio entre os países foi maior, as organizações produtivas expandiram-se, e a expressão "empresa multinacional" - definida por Jacques Maisonrouge da IBM como aquela cujas atividades são concebidas, organizadas e conduzidas em escala mundial - foi muito usada para descrever os conglomerados monopolistas da época (Resende, 2007). Com quase dois terços da produção industrial mundial, os EUA despontaram como um Estado superior a qualquer outro em recursos materiais, financeiros e tecnológicos, e viu suas empresas obrigadas a pensar no mercado internacional (Ghemawat, 2002; Vicentino, 1997). Em 1950, as filiais das multinacionais americanas eram de aproximadamente 7,5 mil, aumentando para mais de 23 mil em 1966 (Hobsbawm, 2008).

Como possuíam know-how maior do que o utilizado para seu negócio principal, elas foram obrigadas a destiná-lo a outros produtos e serviços e atender mercados diferenciados (Miles et al., 1997). A dispersão geográfica estimulou a modernização da administração, pois "não era mais 
possível lidar com o processo de compras, produção e marketing com o mesmo tipo de forma organizacional centralizada e departamentalizada [de outrora]" (Chandler \& Redlich, 1961, p. 12). O novo tipo de empresa foi denominada de multi-function (várias funções), multi-product (vários produtos) e multi-division (várias divisões ou várias unidades), e possuía uma estrutura que já havia sido implementada pela DuPont, pela General Motors, pela Jersey Standard Oil e pela Sears antes dos anos 1940, mas somente após o boom econômico do pós-guerra é que as outras reproduziram esse modelo (Chandler \& Redlich, 1961).

Com as filiais crescendo em proporções exorbitantes, ficou praticamente impossível para os donos do capital acompanharem de perto a condução das atividades organizacionais. A diversificação aumentou a complexidade das situações estratégicas e, se por um lado mais e mais pessoas estavam sendo envolvidas na administração, pelo outro, aqueles que detinham a autoridade final estavam se afastando das operações do dia-a-dia organizacional (Ghemawat, 2002). Uma das mudanças foi a introdução de um nível gerencial intermediário que representava perante os outros funcionários, a equipe dos altos executivos, agora responsável somente pelas grandes metas (Chandler \& Redlich, 1961). Os gerentes profissionalizavam-se e tornavam-se trabalhadores em período integral, tomando todas as decisões estratégicas (Chandler, 1994). As pesquisas corroboram essa percepção e o panorama mudou de 1929, quando 44\% das 200 maiores empresas norteamericanas eram dirigidos por administradores profissionais, que controlavam menos de $20 \%$ do capital votante (Berle \& Means, 1950) para 1963, quando eles já dirigiam 84,5\%, mas controlavam menos de $10 \%$ do capital votante (Larner, 1966).

A profissionalização dos administradores incentivou a formalização do planejamento estratégico, que serviria para direcionar as decisões gerenciais. Na era das multi-divisons, a gestão não poderia ser um comportamento passivo e adaptativo (como se admitia na teoria econômica), e sim uma ação intencional que buscava atingir os resultados desejados, moldar o ambiente e exercer certo controle sobre as variáveis externas. No final dos anos 1950, o professor Andrews (1977) argumentou que ter uma estratégia corporativa implicava que cada unidade, cada departamento e até mesmo cada indivíduo, tivesse um conjunto de objetivos e metas que o fizesse seguir em uma direção escolhida deliberadamente, bem como políticas e planos essenciais para atingir essas metas, estabelecidas de tal maneira que definam o escopo de negócios no qual a empresa está ou quer estar e o tipo de negócio que ela é ou quer ser. O campo da estratégia formal começava a se firmar, e no começo da década seguinte, a maioria das grandes empresas norte-americanas já tinha departamentos e ferramentas específicos de planejamento. Dentre elas, cita-se a análise SWOT, tida como um dos grandes avanços do pensamento estratégico. O modelo de identificação das forças, fraquezas, oportunidades e ameaças (que, em inglês, dão origem ao acrônimo SWOT) traduzia o 
caos de eventos e decisões que o praticante deveria tomar por dia em uma série de passos lógicos, genéricos e analíticos que ajudavam no posicionamento estratégico da organização em relação ao seu ambiente (Ghemawat, 2002).

\section{A 1989: COMPETIÇÃO E INCERTEZA.}

Com a continuação do período de prosperidade do pós-guerra e a evolução paralela da empresa moderna, a terceira geração de gerentes profissionais que se formava queria manter os altos retornos, procurando a diversificação em mercados não explorados e mesmo não relacionados ao negócio principal (Chandler, 1994). Em 1969 algumas corporações dedicaram-se a obter o controle de outras menores, formando conglomerados (Foster, 1985). Essa onda de fusões intensificou o distanciamento entre os donos do capital e os gestores, pois muitas compras eram realizadas sem que o proprietário tivesse o devido conhecimento da indústria adquirida. A administração de mercados não relacionados levou ao aumento do uso de métodos estatísticos para medir o desempenho dos novos investimentos, e à adoção de outros tipos de estruturas, como a matricial (Miles et al., 1997).

Contudo, a partir dos anos 1970, década marcada pela estagnação econômica, a criação dos grandes conglomerados e a diversificação desenfreada foram alvos de restrições governamentais e de críticas teóricas da academia, mesmo porque o retorno financeiro dessa onda de fusões não foi maior do que se as empresas se limitassem à expansão dos seus mercados de origem (Guth, 1980; Foster, 1985). A percepção havia mudado, e o foco era aumentar a participação de mercado do produto mais rentável e aproveitar esse fluxo de caixa para impulsionar outros negócios ainda em desenvolvimento, buscando maior equilíbrio na distribuição dos investimentos dentro do portfólio (Bowman, Singh \& Thomas, 2002). A indústria aproximava-se dos métodos conservadores de gerenciamento e as consultorias puderam protagonizar o planejamento estratégico, apresentando instrumentos ajustados à gestão do portfólio.

O Boston Consulting Group (BCG) criou a Matriz Crescimento-Participação, na qual mostrava como as organizações poderiam otimizar os investimentos, obtendo a maior fatia de mercado possível; a consultoria McKinsey, em 1971, em parceria com a General Electric, lançou a Matriz dos Nove Blocos, que contemplava a atratividade do mercado e posição competitiva, e, segundo eles, seria mais completa do que a matriz da BCG (Ghemawat, 2002). A análise de portfólio, contudo, só começou a ser amplamente utilizada após a primeira crise do petróleo, em 
1973. Com muitos competidores, o mercado em recessão e sem recursos disponíveis, o pensamento estratégico resumia-se a definir prioridades, selecionar as "estrelas" (produtos vencedores) e descartar os "abacaxis" (perdedores). Assim, de certa forma arrependidos pela diversificação mal feita na década anterior, os empresários usaram a análise de portfólio como uma desculpa para livrar-se de negócios sem futuro e repensar seus planos de longo prazo.

Com a segunda crise do petróleo em 1979, a inflação alta e a capacidade ociosa excessiva, começaram a surgir dúvidas sobre o sucesso da análise de portfólio. O chefe da McKinsey criticou o uso de técnicas fechadas e mecanicistas e Mintzberg et al. (2000) justificaram que a Matriz BCG, a Matriz dos Nove Blocos e outras ferramentas como o PIMS (Profit Impact of Market Strategies) não continuaram úteis porque serviam somente para grandes empresas com enorme quantidade de capital, e eram "incapazes de distinguir 'chegar lá' de 'estar lá"” (p. 80).

Entretanto, a desconfiança sobre a eficácia da análise de portfólio não extinguiu a necessidade de se explicar as consequências de determinadas escolhas estratégicas no posicionamento competitivo. Em uma das principais contribuições, foram identificadas cinco forças presentes na indústria (a rivalidade entre os concorrentes; os novos entrantes; a existência de produtos e serviços substitutos; o poder de negociação dos fornecedores e o dos compradores) e três estratégias genéricas (liderança em custo; diferenciação e foco ou nicho de mercado) (Porter, 1980). As ideias descritas por Porter foram bem aceitas nos anos 1980, cujo contexto econômico mostravase mais receptivo a soluções para a competição na indústria. Elas representavam, no entanto, atualizações de trabalhos do professor Joe Bain de Harvard, que na década de 1950 já havia estudado a relação entre preços, margem de lucro, competitividade e atratividade da indústria, e havia identificado três barreiras que permitiam que algumas empresas pudessem elevar preços acima de um nível aceitável sem estimular a entrada de novos competidores: (a) uma vantagem absoluta no preço; (b) um grau significante de diferenciação do produto e; (c) economias de escala (Bain, 1954, 1951; Ghemawat, 2002).

Com a escassez de capital, a análise da competição manteve a sua importância trazendo, porém, alguns elementos distintos. Uma das abordagens sugeria que as operações fossem divididas em tarefas e processos menores (numa cadeia de valor), identificando as atividades que tinham peso maior no custo total (os condutores de custo). Dentre os trabalhos mais conhecidos está novamente o de Porter (1985), cuja contribuição assemelhava-se ao processo oferecido cinco anos antes por um grupo de pesquisadores da Mckinsey, que consistia em uma cadeia de valor, uma maneira de atingir e manter uma vantagem estratégica baseada nos custos (Bales et al., 2000; Ghemawat, 2002, p. 60). A coincidência das ferramentas retrata a relevância da análise de custos para o pensamento estratégico da época, já que professores e consultores pareciam apresentar preocupações similares. 
A segunda crise do petróleo prejudicou as operações de uma grande quantidade de empresas e, o impacto de um problema "externo", razoavelmente incontrolável, chamou a atenção para a variável ambiental na análise organizacional. Acadêmicos e praticantes trabalharam para desenvolver modelos que ajudassem na explicação de situações que envolviam altos níveis de incerteza e imprecisão, como os provocados pelas mudanças no ambiente externo das organizações (Parmar et al., 2010).

Dentre as ferramentas desenvolvidas para lidar com essas incertezas do ambiente, cita-se o Planejamento por Cenários, isto é, a apresentação de futuros possíveis e alternativos que facilitem a elaboração de estratégias. As versões mais modernas dessa ferramenta foram desenvolvidas, de forma paralela, nos EUA e na França a partir do final dos anos 1950. As iniciativas americanas remontam a trabalhos liderados por Herman Khan na Rand Corporation; na experiência francesa, surge o nome do filósofo Gaston Berger como idealizador do Centro de Estudos Prospectivos (Bradfield et al., 2005). Existem indícios de que os grupos se conheciam (Jouvenel, 1965) e usavam os cenários para tratar de questões de interesse geral, como políticas públicas, educação, meio ambiente e urbanização. No entanto, a sua elaboração como suporte para o planejamento estratégico tornou-se mais conhecida a partir dos trabalhos desenvolvidos na Royal Dutch Shell no início dos anos 1970 (Wack, 1985a; 1985b), dada a sua adaptação para se lidar com as incertezas surgidas nas empresas e no mundo dos negócios.

Dentre as teorias, destacam-se algumas que, mesmo não configurando teorias puramente estratégicas, serviam (e servem) como base para a atuação das organizações que queriam adequar seus objetivos às imposições e às incertezas ambientais, como a Ecologia Populacional das Organizações (Hannan \& Freeman, 1977), a Teoria Dependência de Recursos (Aldrich \& Pfeffer, 1976) e a Teoria Institucional (Meyer \& Rowan, 1977). Outra teoria, mais aplicável aos relacionamentos organizacionais com os atores estratégicos do ambiente é a Teoria dos Stakeholders. A noção de stakeholder foi desenvolvida no final da década de 1950 e aperfeiçoada no início dos anos 1960 no Instituto de Pesquisa de Stanford. O conceito central dessa teoria estava ligado à sobrevivência, pois esclarecia que os stakeholders seriam aqueles grupos que garantiriam a continuidade organizacional ou cuja falta de suporte faria com que a organização deixasse de existir (Parmar et al., 2010). Contudo, foi somente nas décadas seguintes, de 1980 e 1990, que ela começou a integrar de forma mais sólida a literatura do planejamento estratégico, atribuindo-se muito do seu atual sucesso ao trabalho de Freeman (1984). O aparente atraso na consolidação da Teoria dos Stakeholders pode ser explicado pelo fato de ela oferecer respostas mais apropriadas aos 
desafios enfrentados pelas organizações nos anos 1980, do que àqueles existentes nos anos 1960, quando foi originada.

\section{A 2010: O VALOR DO CONHECIMENTO.}

Apesar de não se ter uma data exata sobre o início da $3^{\text {a }}$ Revolução Industrial, admite-se que tenha iniciado nas décadas de 1940 e 1950, com o impacto total acontecendo no último quarto do século XX (Galambos, 2005). Essa revolução da tecnologia da informação forneceu a base material indispensável para a criação de uma nova economia que, segundo Castells (1999), é informacional, global e em rede. Ela é informacional porque a produtividade e a vantagem competitiva dependem da capacidade organizacional de gerar, processar e aplicar a informação baseada em conhecimentos; ela é global porque os insumos (capital, trabalho, matéria-prima etc.) a produção, o consumo e a circulação de bens e serviços, estão distribuídos internacionalmente por meio das conexões entre os agentes econômicos; ela está organizada em redes que, possibilitadas pela Internet, dominam a lógica do funcionamento das organizações e imprimem maior descentralização e flexibilidade de gerenciamento, diminuindo as barreiras geográficas que ainda persistem (Castells, 1999; Galambos, 2005).

As rápidas mudanças tiveram reflexos nos processos econômicos, e a nova etapa produtiva passou a exigir mais investimentos em pesquisa e aplicação tecnológica, dependentes, consequentemente, da disponibilidade de enorme volume de capital dos grandes conglomerados empresariais (Vicentino, 1997). Esses novos atores do mercado buscaram estratégias inovadoras para criar vantagens competitivas, em um mundo onde os competidores não são estáticos e não assistem passivamente aos movimentos de uma empresa. Ao invés de somente tentar antecipar as alterações ambientais como ocorrido nas décadas passadas, as organizações começaram a observar e desenvolver seus recursos internos.

Os fundamentos do que posteriormente ficou conhecido como Visão Baseada em Recursos (VBR) podem ser encontrados no trabalho de Penrose (1959), cujas ideias sobre a criação e a sustentação da vantagem competitiva puderam ser mais bem aproveitadas nos anos 1990 (Kor \& Mahoney, 2004). Dentre as contribuições mais modernas, pode-se citar: a de Wernerfelt (1984), para o qual a estratégia deve indicar como os recursos podem garantir uma posição competitiva mais favorável; a de Barney (1991), que explicou as características desejadas dos recursos organizacionais (valor, raridade, inimitabilidade e insubstituibilidade) e como a sua posse influencia na obtenção de uma vantagem competitiva sustentável e; a de Prahalad e Hamel (1990), que 
apontaram a importância de se identificar, cultivar e explorar as competências essenciais, potencialmente capazes de proporcionar o acesso a novos mercados e aumentar a satisfação do consumidor.

A $3^{a}$ Revolução Industrial facilitou o acesso e tornou muito mais disponível aquilo que é considerado a matéria-prima das decisões organizacionais: a informação. O fato de esse recurso ter deixado de ser escasso tornou-o menos eficaz para gerar a desejada vantagem competitiva sustentável. Assim, a partir da metade dos anos 1990, as organizações bem-sucedidas seriam aquelas capazes de processar informações com eficiência, transformando-as em conhecimento, isto é, os estrategistas começaram a recorrer àquilo que sabem como fonte principal para o aumento da produtividade e para a definição dos objetivos estratégicos (Castells, 1999; Davenport \& Volpel, 2001). Como resultado, há um aumento nas organizações do conhecimento, nos trabalhadores do conhecimento e nas estruturas flexíveis; temas como propriedade intelectual e capital intangível tornam-se recorrentes; são valorizadas a pesquisa, a inovação e o desenvolvimento de novos produtos e processos e; surgem cargos como CKO (Chief Knowledge Officer) e CLO (Chief Learning Officer) que complementariam a função de CEO (Chief Executive Officer) (Bowman et al., 2002).

Ao aderirem aos preceitos da Administração do Conhecimento, as organizações deparam-se com inúmeros desafios, dada a sua complexidade. Dúvidas sobre os tipos de conhecimento existentes, a capacidade de transferi-los aos outros e a sua aplicação em toda a organização surgem sem respostas muito claras, mesmo com a existência de alguns trabalhos que, de certa forma, auxiliam nessas questões. Davenport \& Prusak (2003, p. 6), por exemplo, definem o conhecimento organizacional como "uma mistura de valores, informação contextualizada, saberes, técnicas, habilidades, aptidões e capacidades que proporciona uma base para a avaliação e incorporação de novas experiências e informações ". Nonaka e Takeuchi (1997) indicam métodos para criar, disseminar e utilizar o conhecimento em produtos e serviços. Em primeiro lugar, eles retomam a diferença entre o conhecimento tácito - aquele que é pessoal, intrínseco, relacionado à experiência individual, às crenças e valores - e o conhecimento explícito - o qual pode ser formalmente transmitido por meio da linguagem. Em seguida, apontam as suas possibilidades de conversão (socialização, externalização, combinação e internalização) que estimulam a transferência do conhecimento, tornando-o coletivo e acessível.

Outra constatação relevante é a distinção entre o conhecimento conceitual, que significa a capacidade de articular a compreensão de uma experiência, e o conhecimento operacional, que seria a capacidade física de produzir alguma ação. Em outras palavras, além de o conhecimento fazer 
parte da estratégia (know why), ele agora faz parte do estrategista (know how). Em um mundo de mudanças rápidas e descontínuas, a estratégia deixa de ser tratada da forma tradicional, como algo que as empresas “têm”, e passa a ser vista como algo que as empresas (e seus funcionários) "fazem” (Whittington, 2006). A pesquisa em estratégia como prática, que implica observar as rotinas e os padrões de prática corrente e de aprendizado, começa a ganhar visibilidade (Whittington, 1996; Johnson et al., 2007).

Considerar o conhecimento como "o" recurso da organização supõe que a sua utilização deva produzir retornos iguais ou até maiores que os outros recursos. A partir dos anos 1990, começam a ser criadas ferramentas específicas para tal fim, apesar de existirem dificuldades na mensuração do conhecimento. Dentre elas, a mais lembrada é o Balanced Scorecard (BSC), que ficou conhecido a partir dos trabalhos de Kaplan \& Norton (1997; 1992). Visto como um sistema de gestão e planejamento que possibilita à organização esclarecer a sua estratégia e transformá-la em ações, o BSC é, na verdade, um aperfeiçoamento de uma ferramenta francesa das décadas de 1920 e 1930, o Tableau de Bord (Pezet, 2009). A aceitação do BSC deve-se, contudo, ao fato de ser mais completo, incluindo indicadores relacionados à aprendizagem e ao conhecimento organizacional, bem como às condições históricas propícias para a sua disseminação na sociedade da informação.

\section{CONSIDERAÇÕES FINAIS}

$\mathrm{O}$ argumento principal neste artigo, qual seja a influência do contexto nas escolhas estratégicas das organizações, permite realizar uma descrição histórica do desenvolvimento da área da estratégia, bem como indicar algumas tendências, visto que a observação das transformações contemporâneas na política, na economia, na cultura e na sociedade em geral, pode auxiliar na percepção de movimentos estratégicos futuros. Assim, em um exercício preliminar de previsão, são apresentadas duas questões que já aparecem nas discussões organizacionais, e mostram-se como principais candidatas a consolidarem-se em teorias e ferramentas estratégicas: o meio ambiente e a atuação coletiva.

Desde a $1^{\text {a }}$ Conferência das Nações Unidas sobre Ambiente Humano, em 1972, cresce a responsabilidade da sociedade na preservação da natureza: os consumidores parecem mais propensos a considerarem as ações ecológicas das organizações como critérios de escolha, mesmo com a permanente importância do preço e da qualidade na decisão de compra; os governos têm instituído novas leis que regulam as atividades organizacionais, limitando o impacto que a indústria pode causar na natureza e/ou incentivando mecanismos de mercado que de certa foram 
recompensem práticas ecologicamente desejadas (e.g. ICMS ecológico, mercados de carbono etc.); as ONGs chamam a atenção para ações perniciosas e buscam formar a opinião da população para posicionar-se contrariamente a possíveis abusos. Esta preocupação internacional estimulou as empresas a adotarem comportamentos aparentemente mais ecológicos, investindo na criação de tecnologias mais limpas e eficientes e criando novos cargos e departamentos, tornando a gestão da sustentabilidade uma área destinada, como qualquer outra, a dar resultados positivos.

$\mathrm{Na}$ área da estratégia, ainda não existem modelos e teorias específicos para tratar do meio ambiente. Dentre as propostas existentes, algumas são mais radicais, como o sistema econômico “alternativo" proposto por Hawken, Lovins e Lovins (1999), e outras mais genéricas, como a de Porter e Reinhardt (2007) e a de Senge et al. (2009), que abordam o desafio organizacional de sobreviver às transformações na relação sociedade-ambiente natural. As outras contribuições resumem-se a um conjunto de dicas e adaptações a certificações que atendem satisfatoriamente aos interesses econômicos de diminuição de custos e aumento de receita, mas podem tornar as ações ecologicamente ineficazes.

A dificuldade na criação de modelos mais acurados deve-se ao fato de a natureza possuir algumas características que ora a distingue e ora a aproxima das outras variáveis ambientais como a política, a demografia, a tecnologia e a cultura etc. A primeira é o fato de a natureza ser a fornecedora (direta e indireta) de todos os recursos organizacionais, além de ser o destino dos resíduos gerados, sendo que o desequilíbrio nessa relação deverá, invariavelmente, afetar na sobrevivência organizacional. Em segundo lugar, ainda existem incertezas sobre a proporção das consequências geradas pela ação humana, ou seja, não se sabe como o funcionamento do sistema natural poderá responder caso a destruição continue acelerada e nem mesmo qual a capacidade humana de reconstruir as áreas, a biodiversidade e as interações naturais que forem prejudicadas. Por fim, a escala temporal da natureza é diferente da escala temporal dos sistemas sociais, que não estão adaptados aos desafios de longo prazo impostos pelo meio ambiente.

A segunda tendência estratégica é derivada do relacionamento entre as organizações e seus stakeholders, modificado pelas novas ferramentas de comunicação. A evolução da sociedade em rede, possibilitada pelas tecnologias disponíveis, incentivou a atuação coletiva e a aumentou a capacidade de mobilização dos clientes, dos funcionários e das próprias organizações. Os consumidores têm colaborado entre si para potencializar seus ganhos (como nos sites de compras coletivas), e aumentar a eficácia de suas reclamações, por meio dos blogs e redes sociais. Consideradas fontes alternativas de feedback e a cada dia mais relevantes para a tomada de decisão, essas ferramentas estimularam a contratação de profissionais dedicados exclusivamente a monitorar 
opiniões, avaliar gostos, moderar discussões, responder às críticas e dúvidas, ou mesmo impulsionar uma campanha publicitária, sendo vistos como verdadeiros pesquisadores virtuais.

Dentre os exemplos mais específicos de ações coletivas, pode-se citar, primeiramente, o crowdsourcing. Grandes empresas, com capital financeiro suficiente, aproveitam a colaboração coletiva para obter recursos menos disponíveis e mais valorizados, como a criatividade e o próprio conhecimento. Os setores beneficiados, como o de desenvolvimento de softwares, o de design de produtos, o de publicidade e propaganda, a indústria cultural e o terceiro setor, conseguem envolver colaboradores e voluntários por meio de promoções nas quais oferecem recompensas por boas inovações, pagamento por produtividade ou outros mimos, como viagens, reconhecimento público e aparições na grande mídia. Dentre as derivações do crowdsourcing pode-se citar o crowdfunding (financiamento coletivo) - que propicia que pessoas com boas ideias e sem recursos obtenham o apoio de pessoas com bons recursos mas sem ideias - e o coworking - modalidade onde há o compartilhamento de espaços, móveis, meios de transporte etc., útil para empreendedores com atividades similares.

Além de fortalecer as ações pretendidas e melhorar a tomada de decisão com a diversidade de informações e opiniões, a atuação coletiva pode diminuir o impacto que as organizações causam nos recursos escassos, aproximando essa tendência dos desejos de preservação da natureza. Mais recente que as discussões sobre meio ambiente, a noção de coletividade precisa ser mais pesquisada e sistematizada para estabelecer-se como uma estratégia mais robusta, visto que os textos sobre o tema tratam do seu conceito (Arolas \& Guevara, 2012) e de como ela tem mudado as relações sociais em geral (Wexler, 2011).

Relacionar história e estratégia é um exercício que depende, sobretudo, de uma descrição aprimorada de uma série de acontecimentos econômicos, culturais, tecnológicos e políticos etc. que estimularam as escolhas feitas pelas organizações. Consciente das dificuldades, não se tentou ser exaustivo no relato histórico (o que seria explicitamente impossível) e nem na exposição sobre estratégia.

De qualquer forma, a elaboração deste ensaio permitiu indicar explicações adicionais para a evolução do pensamento estratégico, além de direcionar os estudos da área, já que são mencionadas, mesmo que superficialmente, boa parte das teorias e ferramentas desenvolvidas a partir do século XX. Ainda, a diferença por vezes encontrada, entre o surgimento de determinada teoria ou ferramenta e sua ampla aceitação e disseminação, fortalece o argumento sobre como as condições históricas podem ser determinantes nas escolhas feitas pelas organizações.

Por fim, posicionar historicamente o pensamento estratégico não revela, de forma alguma, qualquer propensão a tratá-lo como uma simples resposta adaptativa às transformações ambientais. 
Pelo contrário, as organizações são essenciais para a sociedade moderna, e devem usar a sua capacidade de influência para promover, muito mais do que os apreciados retornos financeiros, as necessárias melhorias no acesso a bens e serviços e nas condições de vida.

\section{REFERÊNCIAS}

Aldrich, H. E., \& Pfeffer, J. (1976). Environments of Organizations. Annual Review of Sociology, 2, 79-105.

Andrews, K. (1977). El concepto de estrategia de la empresa. Ediciones Universidad de Navarra S.A.: Barcelona.

Arolas, E. E.. \& Guevara, F. G. L. (2012). Towards and integrated crowdsourcing definition. Journal of Information Science, 38 (2), 189-200.

Bain, J. S. (1954). Economies of Scale, Concentration, and the Condition of Entry in Twenty Manufacturing Industries. The American Economic Review, 44 (1), 15-39.

Bain, J. S. (1951). Relation of Profit Rate to Industry Concentration: American Manufacturing, 1936-1940. The Quarterly Journal of Economics, 65 (3), 293-324.

Bales, C., Chatterjee, C., Gogel, D., \& Puri, A. (2000). The microeconomics of industry supply. The McKinsey Quarterly, June, 21-28 Recuperado de: http://www.kellogg.northwestern.edu/faculty/vohra/ftp/miin00.pdf

Barnard, C. I. (1938). The Functions of the Executive. Cambridge: Harvard University Press.

Barney, J. (1991). Firm Resources and Sustained Competitive Advantage. Journal of Management, $17(1), 99-120$.

Barret, F. J., \& Srivastva, S. (1991). History as a Mode of Inquiry in Organizational Life: a Role for Human Cosmology. Human Relations, 44 (3), 231-254. 
Barros, J. A. (2004). Os Campos da História: uma introdução às especialidades da História. Revista HISTEDBR On-line, 16, 17-35.

Bedeian, A. G., \& Phillips, C. R. (1990). Scientific Management and Stakhanovism in the Soviet Union: a Historical Perspective. International Journal of Social Economics, 17 (10), 28-35.

Berle Jr., A. A., \& Means, G. C. (1950). The Modern Corporation and Private Property. New York: Macmillan.

Booth, C., \& Rowlinson, M. (2006). Management and organizational history: prospects. Management \& Organizational History, 1 (1), 5-30.

Borges, V. P. (1993). O Que é História. São Paulo: Brasiliense.

Bowman, E.H., Singh, H., \& Thomas, H. (2002). The Domain of Strategic Management: History and Evolution In A. Pettigrew, H. Thomas, \& R. Whittington. Handbook of Strategy and Management (cap. 2, pp. 31-51). London: Sage Publications.

Bradfield, R., Wright, G., Burta, G., Cairns, G. van der Heijden, K. (2005). The origins and evolution of scenario techniques in long range business planning. Futures 37, 795-812.

Castells, M. (1999). A era da informação: economia, sociedade e cultura, v. 1. São Paulo: Paz e Terra.

Chandler, A. D. (1994). The competitive performance of U.S. industrial enterprises since the Second World War. Business History Review, 68 (1), 1-72.

Chandler, A. D., \& Redlich, F. (1961). Recent Developments in American Business Administration and Their Conceptualization. Business History Review, 35, 1-27.

Clark, P., \& Rowlinson, M. (2004). The treatment of history in organization studies: towards an 'historic turn'? Business History, 46 (3), 331-352.

Costa, A. S. M., Barros, D. F., \& Martins, E. M. (2010). Perspectiva Histórica em Administração: Novos Objetos, Novos Problemas, Novas Abordagens. Revista de Administração de Empresas, 50 (3), 288-299.

Davenport, T. H., \& Prusak, L. (2003). Conhecimento Empresarial: como as organizações gerenciam o seu capital intelectual, $14^{\mathrm{a}}$ ed. Rio de Janeiro: Elsevier.

Davenport, T. H., \& Volpel, S. C. (2001). The rise of knowledge towards attention management. Journal of Knowledge Management, 5 (3), 212-221. 
Fayol, H. (1930). Administration industrielle et générale. Paris: Dunod.

Foster, L.W. (1985). From Darwin to Now: The Evolution of Organizational Strategies. Journal of Business Strategies, 5, 94-98.

Freitas-Filho, A. (1989). História Econômica e História de Empresa: Algumas Reflexões Metodológicas. Ensaios FEE, 10 (1), 168-177.

Freeman, R. E. (1984). Strategic Management: a Stakeholder Approach. Boston: Pitman.

Galambos, L. (2005). Recasting the Organizational Synthesis: Structure and Process in the Twentieth and Twenty-First Centuries. Business History Review, 79 (1), 1-38.

Ghemawat, P. (2002). Competition and Business Strategy in Historical Perspective. Business History Review, 76 (1), 37-74.

Gras, N.S.B. (1936). Fifty Years of Development in Industrial Organization. Business Historical Society: Bulletin of the Business Historical Society, 10 (1), 7-15.

Guth, W. (1980). Corporate Growth Strategies. Journal of Business Strategy, 1 (2), 56-62.

Hannan, M. T., \& Freeman, J. (1977). The Population Ecology of Organizations. The American Journal of Sociology, 82 (5), 929-964.

Hawken, P., Lovins, A., \& Lovins, L. H. (1999). Capitalismo Natural. São Paulo: Cultrix.

Hobsbawm, E. (2008). A Era dos Extremos: o breve século XX (1914-1991), $2^{a}$ ed. São Paulo: Companhia das Letras.

Howell, C. (1995). Toward a History of Management Thought. Business and Economic History, 24 (1), 41-50.

Johnson, G., Langley, A., Melin, L., \& Whittington, R. (2007). Strategy as Practice: Research Directions and Resources. Cambridge: Cambridge University Press.

Jouvenel, B. (1965). Futuribles. RAND's International Seminar 1964. Recuperado de http://www.rand.org/ em janeiro de 2013.

Kaplan, R. S., \& Norton, D. (1997). A estratégia em ação: balanced scorecard. Rio de Janeiro: Campus. 
Kaplan, R. S., \& Norton, D. (1992). The Balanced Scorecard - Measures that Drive Performance. Harvard Business Review. Jan-Fev, 71-80.

Kipping, M. (1997). Consultancies, institutions and the diffusion of Taylorism in Britain, Germany and France, 1920s to 1950s. Business History, 39 (4), 67-83.

Kor, Y. Y., \& Mahoney, J. T. (2004). Edith Penrose's (1959) Contributions to the Resource-based View of Strategic Management. Journal of Management Studies, 41 (1), 183-191.

Larner, R. J. (1966). Ownership and Control in 200 Largest Non-Financial Corporations, 1929 and 1963. American Economic Review, 56 (4), 777-787.

Meyer, J. W., \& Rowan, B. (1977). Institutionalized Organizations: Formal Structure as Myth and Ceremony. The American Journal of Sociology, 83 (2), 340-363.

Miles, R.E., Snow, C.C., Mathews, J.A., Miles, G., \& Coleman Jr., H.J. (1997). Organizing in the Knowledge Age: Anticipating the Cellular Form. Academy of Management Executive, 11 (4), 7 24.

Mintzberg, H., Ahlstand, B., \& Lampel, J. (2000). Safári da Estratégia. Porto Alegre: Bookman.

Morgan, S. L. (2006). Transfer of Taylorist ideas to China, 1910-1930s. Journal of Management History, 12 (4), 408-424.

Motta, F. C. P., \& Bresser-Pereira, L. C. (1980). Introdução à Organização Burocrática. São Paulo: Editora Brasiliense.

Motta, F.C.P. (1998). Teoria Geral da Administração. São Paulo: Pioneira.

Nelson, D. (1974). Scientific Management, systematic management, and labor, 1880-1915. Business History Review, 48 (4), 479-500.

Nonaka, I.; Takeuchi, H. (1997). Criação de Conhecimento na Empresa : como as empresas japonesas geram a dinâmica da inovação. Rio de Janeiro: Campus.

Parmar, B. L., Freeman, R. E., Wicks, A. C., Harrison, J. S., Colle, S., \& Purnell, L. (2010). Stakeholder Theory: The State of the Art. The Academy of Management Annals, 4 (1), 403-445.

Penrose, E. T. (1959). The theory of the growth of the firm. New York: John Wiley \& Sons.

Pezet, A. (2009). The history of the French tableau de bord (1885-1975): evidence from the archives. Accounting Business and Financial History, 19 (2), 103-125. 
Porter, M. E. (1985). Competitive Advantage: creating and sustaining superior performance. New York: Free Press.

Porter, M. E. (1980) Competitive Strategy: techniques for analyzing industries and competitors. New York: Free Press.

Porter, M. E., \& Reinhardt, F. L. (2007). Grist: A Strategic Approach to Climate, Harvard Business Review, 85 (10), 22-25.

Prahalad, C. K, \& Hamel, G. (1990). The Core Competence of the Corporation, Harvard Business Review, May-June, 78-90.

Resende, C. (2007). História Econômica Geral. $9^{a}$ Ed. São Paulo: Contexto.

Sasaki, S. (1992). The introduction of scientific management by the Mitsubishi Electric Engineering Co. and the formation of an organised scientific management movement in Japan in the 1920s and 1930s. Business History, 34 (2), 12-27.

Sears, M. (1956). The American Business Man at the Turn of the Century. Business History Review, 30 (4), 382-443.

Senge, P., Smith, B., Kruschwitz, N., Laur, J., \& Schley, S. (2009). A Revolução Decisiva: como indivíduos e organizações trabalham em parceria para criar um mundo sustentável. Rio de Janeiro: Elsevier.

Stevens, M. (2001). Extreme Management: What They Teach at Harvard Business School's Advanced Management Program. New York: Warner Bros, Inc.

Tedlow, R.S., Bettcher, K.E., Purrington, C.A. (2003). The Chief Executive Officer of the Large American Industrial Corporation in 1917. Business History Review, 77(4), 687-701.

Vargas, N. (1985). Gênese e Difusão do Taylorismo no Brasil. In ANPOCS, Ciências Sociais Hoje (cap. 5, pp.155-189). São Paulo: Cortez.

Vicentino, C. (1997). História Geral. São Paulo: Scipione.

Vizeu, F. (2010). Potencialidades da Análise Histórica nos Estudos Organizacionais Brasileiros. Revista de Administração de Empresas, 50 (1), 37-47.

Wack, P. (1985a). Scenarios: Uncharted waters ahead. Harvard Business Review, 63 (5), 73-89.

Wack, P. (1985b). Scenarios: Shooting the rapids. Harvard Business Review, 63 (6), 139-150. 
Wernerfelt, B. (1984). A Resourced-Based View of the firm. Strategy Management Journal, 5 (2), 171-180.

Wexler, M. N. (2011). Reconfiguring the sociology of the crowd: exploring crowdsourcing. International Journal of Sociology and Social Policy, 31 (1), 6-20.

Whittington, R. (2006). Completing the Practice Turn in Strategy Research. Organization Studies, 27 (5), 613-634.

Whittington, R. (1996). Strategy as Practice. Long Range Planning, 29 (5), 731-735.

Zald, M. (1996). More Fragmentation? Unfinished business linking the social sciences and the humanities. Administrative Science Quarterly, 41 (2), 251-261.

Recebido: 27/07/2013

Aprovado: 21/09/2013 